\title{
A (in)visibilidade da atividade de revisão de textos acadêmicos: um outro na teia dos sentidos
}

\section{(In)visibility in academic-text proofreading: an other in the web of meanings}

Vanessa Fonseca Barbosa ${ }^{1}$ Maria da Glória Corrêa di Fanti² 1,2 Pontifícia Universidade Católica do Rio Grande do Sul, Escola de Humanidades, Programa de Pós-Graduação em Letras,

Doutora em Letras, área de concentração em Linguística, pela Pontifícia Universidade Católica do Rio Grande do Sul (PUCRS) e pesquisadora
do Grupo Tessitura: Vozes em (Dis)curso (PUCRS/ do Grupo Tessitura: Vozes em (Dis)curso (PUCR CNPq)

(D) https://orcid.org/0000-0003-2901-015X

mail: vanessafonbar@gmail.com

Doutora em Linguística Aplicada e Estudos da de São Paulo e professora-pesquisadora do Programa de Pos-Graduacáa em Letras da Esco de Humanidades da PUCRS. Coordenadora do Grupo Tessitura: Vozes em (Dis)curso (PUCRS/ do C). Bolsista do Produlvidade em Pusa
RESUMO: Este artigo, com base na teoria bakhtiniana e na ergologia, tem o objetivo de analisar facetas da atividade do revisor de texto acadêmico Para tanto, observa relações de alteridade a partir de interações entre uma revisora e uma doutoranda durante parte do processo de revisão textual de uma tese de doutoramento. A reflexão contempla a análise de enunciados, via excertos de textos e respectivos comentários, no que se refere à relação entre as palavras da revisora e as palavras da doutoranda. Como resultado, percebemos que, mesmo se estabelecendo por grande grau de invisibilidade, a atividade de revisão instaura um importante outro, constitutivo da teia dos sentidos construídos na versão final do trabalho revisado.

Palavras-chave: Revisão de textos acadêmicos; Alteridade; Dialogismo; Invisibilidade do trabalho; Linguagem e trabalho.

ABSTRACT: Based on Bakhtin's theory and on ergology, this paper seeks to analyze aspects of the work of academic-text proofreaders. It observes alterity relationships from interactions between a proofreader and a Doctorate candidate during part of the proofreading process for a Doctorate dissertation. Through excerpts from the text and respective commentary on them, the paper analyzes statements pertinent to the relationship between the proofreader's words and the Doctorate candidate's words. As a result we realized that, while implying a high degree of invisibility, proofreading brings to the process an important other, who constitutes the web of meanings that make up the final version of the proofread work.

Keywords: Academic-text proofreading; Alterity; Dialogism; Work invisibility; Language and work. 
A

relação entre linguagem e trabalho tem nos provocado a desenvolver diferentes reflexões interdisciplinares, em especial a partir da interface entre a perspectiva dialógica da linguagem e a abordagem ergológica do trabalho, tendo em vista a importância da análise de práticas de linguagem para a compreensão da complexidade de atividades distintas. ${ }^{1}$ Se, por um lado, todo trabalho se vale direta ou indiretamente da linguagem para ser desenvolvido, por outro, há trabalhos que têm a linguagem como foco principal de sua existência. Esse é o caso da atividade de revisão textual. ${ }^{2}$

Ainda que, na esfera cotidiana, não seja incomum a busca por serviços de um profissional da área da revisão de textos, na esfera acadêmica, tal demanda se intensifica seja em produções contínuas, como artigos, capítulos de livros e livros, seja em trabalhos correspondentes a titulações, como teses, dissertações e monografias. É recorrente a solicitação dos orientadores e/ou membros de bancas de avaliação dos trabalhos acadêmicos de que o texto apresentado seja enviado para a revisão antes da entrega final, o que aponta para a busca de qualificação da versão final do texto. Estranha-se, no entanto, o silenciamento dessa atividade, considerando que, na maioria das vezes, não se faz menção e/ou registro a essa revisão nos trabalhos vindos a público.

Outra questão que revela a complexidade dessa atividade está relacionada ao fato de que há poucos espaços institucionais para o exercício da revisão de textos que reconhecem esse fazer como uma função profissional, seja pública ou privada, acarretando a expansão dos chamados profissionais liberais. Isso significa que é muito maior o número de revisores

\footnotetext{
Di Fanti $(2017,2013,2012,2005)$, Barbosa $(2017,2012)$, Barbosa e Di Fanti (2017) e Schwartz, Di Fanti e Barbosa (2016).

2 Este artigo apresenta uma reflexão reformulada e aprofundada de parte da pesquisa de doutorado de Vanessa Fonseca Barbosa, defendida em dezembro de 2017, no Programa de Pós-Graduação em Letras (PPGL) da Pontifícia Universidade Católica do Rio Grande do Sul (PUCRS), sob a orientação da
} professora Maria da Glória Corrêa Di Fanti. que fazem a revisão de modo isolado, de maneira bastante diversificada e com quase nenhum reconhecimento do mercado em que atuam, o que contribui também para o silenciamento e a invisibilidade do trabalho. Esses aspectos, portanto, ratificam a necessidade de reflexões que busquem melhor compreender e oferecer subsídios teórico-metodológicos de análise e reflexão para o fazer profissional do revisor de textos em geral e de textos acadêmicos em particular.

Além desse silenciamento, estudos realizados por Barbosa $(2012,2017)$ e a sua experiência com revisão de textos acadêmicos revelam que o trabalho do revisor de textos é marcado por uma diversidade de perspectivas por parte dos que o solicitam, que podem ser resumidas em três aspectos essenciais: i) uma abordagem gramatical, "um fazer apático, mecânico, um aglomerado de aplicações de regras da gramática normativa, sem que se considere o sentido e o contexto discursivo de inserção do texto" (Barbosa, 2012, p. 19); ii) um fazer constituído pela coautoria, no qual o fazer do revisor é comparado ao de um coautor, responsável por participar da reformulação de várias passagens da produção revisada a partir de diálogos estabelecidos com o autor da escrita durante o processo em que a atividade se desenvolve; e iii) uma atividade cujo trabalhador é o único responsável pela reescrita de todo o texto, assim, espera-se do profissional de textos a reescrita completa de todos os períodos com problemas gramaticais, estruturais e/ou semânticos. Nesta abordagem, bastante questionável, o revisor é visto como aquele que deveria fazer a maior parte do trabalho que caberia ao autor do texto, mediante uma combinada quantia em pagamento.

Essas observações são lacunares, uma vez que não recobrem a complexidade e a diversidade do trabalho de revisão, que emerge no processo, desde a sua contratação até a sua finalização. Afinal, que atividade é essa que, embora tenha uma grande demanda, é pouco reconhecida na 
sociedade? Que particularidades são constitutivas da atividade de revisão de textos acadêmicos? Se do ponto de vista do produto da revisão do trabalho acadêmico em geral não há dúvida quanto ao reconhecimento de sua importância, o que dizer da atividade de revisão considerando o trabalho do revisor?

Temos observado que como objeto científico a revisão de textos necessita de maior discussão e espaço acadêmico, pois, ainda que seja bastante solicitada nesse meio, as pesquisas sobre o trabalho de revisão textual, principalmente a realizada em gêneros acadêmicos, ainda não são frequentes. Tal constatação aponta para a importância de estudos sobre esse fazer complexo, já que investigações científicas podem auxiliar tanto o profissional de revisão de textos acadêmicos quanto o pesquisador que solicita a revisão.

Desse modo, propomos neste artigo problematizar o trabalho do revisor de tese de doutorado, observando relações de alteridade a partir de interações entre uma revisora e uma doutoranda durante parte do processo de revisão textual de sua tese. ${ }^{3} \mathrm{~A}$ reflexão contempla a análise dos enunciados postos em relação, via excertos de textos e respectivos comentários, no que se refere a movimentos de alteridade entre as palavras da revisora e as palavras da doutoranda que dialogam e se complementam, seja pela aproximação e/ou concordância dos seus dizeres, seja pelo afastamento e/ou discordância. Tais práticas dão pistas do imbricamento de vozes dos sujeitos envolvidos no trabalho de elaboração do texto final, considerando relações dialógicas e de alteridade, signos ideológicos postos em relação, bem como acentos valorativos que emergem da atividade e constituem as normas e renormalizações desse fazer complexo e multifacetado.

A escolha da revisão de tese de doutorado deve-se ao fato de ser a tese o gênero correspondente a mais alta titulação acadêmica.
Para o desenvolvimento da reflexão, este artigo está organizado em três seções, seguidas das considerações finais. Na primeira, apresentamos considerações teóricas relativas à perspectiva dialógica da linguagem. $\mathrm{Na}$ segunda seção, discorremos sobre a abordagem ergológica do trabalho. Por fim, na terceira, dedicamo-nos à análise de dois recortes, compostos por excertos da interação estabelecida entre os sujeitos da pesquisa.

\section{Perspectiva dialógica da linguagem}

Para o Círculo de Bakhtin, todo discurso está em inter-relação com o discurso do outro, ou seja, constitui-se a partir de outros discursos. ${ }^{4}$ Esse reconhecimento do outro remete à alteridade e ao dialogismo, propriedades que perpassam a constituição do discurso, do sentido e do sujeito. ${ }^{5}$

Tal perspectiva está presente no conjunto da obra bakhtiniana e pode ser observada desde a noção de língua, que tem como fundamento a interação entre diferentes sujeitos. Seguindo Volóchinov (2017, p. 224), apresentamos cinco características resumidas da língua: a língua é uma realidade concreta; a língua realiza-se por meio da "interação sociodiscursiva dos falantes"; "as leis da formação da língua são leis sociológicas em sua essência”; a criação da língua está em relação orgânica com os sentidos e os valores ideológicos; e "a estrutura do enunciado é uma estrutura puramente social", ou seja, se constitui entre os falantes. ${ }^{6}$ Essas características remetem ao fato de a interação discursiva ser a realidade fundamental da língua, por isso os signos

${ }^{4}$ O Círculo de Bakhtin é constituído por um grupo de intelectuais de formações e interesses distintos que, de 1919 a 1929, se reunia na Rússia para refletir acerca das mais variadas questões filosóficas. Os principais compones da área da linguagem eram M. Bakhtin. V. N. Volochínov e P. N. Medvedev (FARACO, 2009).

5 Di Fanti (2017), em Discurso, dialogismo e atividade de trabalho: a constitutiva e tensa relação com o outro, aprofunda essa questão.

6 Os grifos nas citações deste artigo são dos autores consultados. 
(sempre ideológicos) adquirem valor social nas relações interindividuais. Os signos surgem "entre indivíduos socialmente organizados no processo de sua interação", o que significa que as mudanças das interações acarretam mudança do signo (VOLÓCHINOV, 2017, p. 109).

Nessa perspectiva, o signo ideológico é multiacentuado, característica que revela um cruzamento de acentos sociais de valor que o capacita a viver, movimentar-se e desenvolver-se. Conforme Volóchinov (2017, p. 113), "qualquer signo ideológico tem duas faces", isto é, tem a capacidade de adquirir diferentes valores nas interações: "qualquer xingamento vivo pode se tornar um elogio, qualquer verdade viva deve inevitavelmente soar para muitos como uma grande mentira". Essas características, próprias da dialética do signo, associam-se ao fato de o signo ideológico não só refletir mas também refratar realidades. Enquanto o reflexo está relacionado com valores sócio-historicamente reiteráveis pela significação compartilhada na memória discursiva dos sujeitos, a refração está ligada à multiplicidade de sentidos, aos diferentes acentos que recebe na particularidade das enunciações. Sendo assim, o signo carrega em si a possibilidade de não só absorver aspectos de dada realidade, mas também de complementá-la, alterá-la, modificá-la, de dar-lhe diferentes tonalidades a depender dos valores que compartilha e das relações que estabelece com outros signos no processo de interação. ${ }^{7}$

A palavra, sob esse ponto de vista, é compreendida como um signo ideológico por natureza. Configura-se como um "fenômeno ideológico par excellence" e como "o medium mais apurado e sensível da comunicação social" (VOLÓCHINOV, 2017, p. 98; 99). Por isso, a palavra tem a capacidade de pluriacentuação, pode se impregnar de diferentes valorações emotivovolitivas no jogo de instauração de sentidos que ela engendra. A valoração dá

7 Sobre essa reflexão, ver Barbosa; Di Fanti (2017). o tom à palavra, à linguagem, revelando a apreensão axiológica do mundo. De acordo com Volochínov (2011, p. 159-160), "a entoação estabelece um vínculo estreito entre a palavra e o contexto extraverbal: a entoação viva parece conduzir a palavra além das fronteiras verbais" e é nesses termos que importa observar e analisar a linguagem, buscando compreendê-la nesse jogo entre acentos de valor e estabelecimento de sentidos nos enunciados produzidos.

Nesse contexto, o enunciado emerge como unidade real das interações discursivas, uma vez que o discurso tem existência somente na "forma de enunciados concretos de determinados falantes, sujeitos do discurso" (BAKHTIN, 2016a, p. 28). O centro organizador de qualquer enunciado, como observa Volóchinov (2017, p. 216), "não está no interior, mas no exterior: no meio social que circunda o indivíduo". Logo, a orientação do enunciado é social, ele é delimitado pelos participantes do evento em uma dada situação: "essa situação mais próxima e os participantes sociais imediatos determinam a forma e o estilo do enunciado" (p. 207). Tais particularidades conduzem à noção de gêneros do discurso, "tipos relativamente estáveis de enunciados", constituídos por forma composicional, estilo de linguagem e tema, que respondem a determinadas esferas de interação discursiva (BAKHTIN, 2016a, p. 12). Nessa relação, os enunciados representam as mudanças mais sensíveis ocorridas na sociedade, pois os gêneros se originam e se modificam a partir das práticas sociais.

A expressão do enunciado, como propala Bakhtin (2016a, p. 58), "nunca pode ser entendida e explicada até o fim levando-se em conta apenas o seu conteúdo centrado no objeto e no sentido". É necessário considerar "a relação do falante com os enunciados do outro", a resposta dada ao outro em relação ao contexto. $\mathrm{O}$ enunciado constitui-se "no processo de interação e luta" com outros enunciados e é por isso "pleno de tonalidades dialógicas" 
(p. 59). Como elo na cadeia da comunicação discursiva, o enunciado está ligado a enunciados que o precedem e enunciados que o sucedem, configurando o outro como participante ativo do discurso. Ao outro se faz projeções, se responde e se antecipa dizeres, o que permite dizer que "todo enunciado é repleto de variadas atitudes responsivas a outros enunciados" (BAKHTIN, 2016a, p. 57).

Por essa concepção dialógica, podemos dizer que, embora seja singularizado pelo falante, o enunciado não é nele originário; encontramos sempre o objeto do dizer já enunciado, acentuado por múltiplas vozes no continuum da cadeia discursiva (BAKHTIN, 2016a). O discurso, a língua em sua integridade concreta e viva, é considerado na tessitura das interações sociais (BAKHTIN, 2015a). As múltiplas vozes sociais que dão tonalidade ao enunciado, ao discurso, sejam mais ou menos consoantes ou destoantes, permitem compreender que, muito além da superfície, o enunciado é permeado por uma constitutiva relação com dizeres outros, uma diversidade de vozes que se tocam de diferentes modos e que formam o heterodiscurso dialogizado (BAKHTIN, 2015b).

O discurso, sob essa perspectiva, "surge no diálogo como sua réplica viva, forma-se na interação dinâmica com o discurso do outro no objeto" (BAKHTIN, 2015b, p. 52). Nesse caminho, o "discurso concreto (enunciado) encontra o objeto para o qual se volta sempre [...] já difamado, contestado, avaliado, envolvido por uma fumaça que o obscurece ou, ao contrário, pela luz de discursos alheios já externados a seu respeito" (p. 48). O discurso, como destaca o pensador russo, "entra nesse meio dialogicamente agitado e tenso de discursos, avaliações e acentos alheios, entrelaça-se [com uns], afasta-se de outros, cruza-se com terceiros [...]".

Para Bakhtin (2010), há uma arquitetônica da responsabilidade que, tendo como centro a relação eu/outro, pressupõe a existência de dois lugares diferentes, exclusivos, em que um não pode ocupar o lugar do outro, uma vez que são centros de valor essencialmente diferentes, embora estejam intrinsecamente correlacionados. Nessa indissociável relação, cada um é responsável pelo seu ato e não tem como se eximir dessa responsabilidade. Do mesmo modo, cada indivíduo, a partir de múltiplas interações, é marcado pela sua singularidade, já que tem um horizonte concreto único que nunca vai coincidir com o horizonte social de outra pessoa. Os diferentes horizontes são associados aos movimentos de empatia (aproximação) e exotopia (distanciamento) e ao excedente de visão (BAKHTIN, 2011). Para aproximar-se do horizonte de outro, faz-se necessário entrar em aproximação empática com o outro, colocar-se provisoriamente no lugar do outro, buscando apreender e sentir a vida tal como ele para, em seguida, distanciar-se. O retorno ao próprio lugar marca a exotopia, o distanciamento do lugar do outro, que provoca a revelação, ainda que parcial, do outro, via excedente de visão. Assim, a empatia e a exotopia mantêm relação orgânica entre si e não podem ser tomadas de modo isolado; são movimentos interdependentes e necessários que não só marcam a constitutiva relação entre o eu e o outro, mas também a singularidade de cada um deles em ver no outro o que ele próprio não pode ver sozinho.

Nessa relação, cabe destacar a relação empreendida com a palavra do outro. Conforme Bakhtin, além das palavras da língua, que não pertencem a ninguém, há outras duas acepções que interessam para esta reflexão: a palavra alheia e a minha palavra (BAKHTIN, 2016a, p. 53). A "palavra alheia" é a palavra dos outros, por isso também chamamos neste trabalho de "palavra do outro", e a "minha palavra" é a palavra operada pelo sujeito do discurso, "em uma situação determinada, com uma intenção discursiva determinada", marcada pela expressividade do falante, por isso também a designamos como "palavra própria". Tanto a palavra do outro quanto a palavra própria possuem expressividade, isto é, expressam posição valorativa do sujeito do discurso em uma dada interação social. 
A experiência discursiva de qualquer pessoa, destaca Bakhtin (2016a, p.54), "se forma e se desenvolve em uma interação constante e contínua com os enunciados individuais dos outros. Tal experiência, de certo modo, configura um "processo de assimilação - mais ou menos criador - das palavras do outro", pois o "nosso discurso, isto é, os nossos enunciados, [...] é pleno de palavras dos outros, de um grau vário de alteridade ou de assimilidade [...]". As palavras dos outros, de acordo com o filósofo da linguagem, são constituídas de expressão, tom valorativo, que "assimilamos, reelaboramos e reacentuamos". As fronteiras não são reconhecidas e marcadas. Quando a palavra do outro é apreendida e destacada como do outro no enunciado, estabelece-se um tipo de alternância dos sujeitos do discurso, cuja delimitação é enfraquecida já que "a expressão do falante penetra através desses limites e se dissemina no discurso do outro", podendo transmiti-la em "tons irônicos, indignados, simpáticos [...]" (BAKHTIN, 2016a, p. 59). ${ }^{8}$

Como, neste artigo, propomos problematizar o trabalho do revisor de textos acadêmicos, via análise de movimentos de alteridade entre as palavras de uma revisora e as palavras de uma doutoranda no processo de revisão da tese de doutoramento, é de suma importância discutir a relação empreendida com a palavra do outro. Ainda que na versão final do trabalho revisado não seja possível delimitar a palavra da revisora, e nem se espera isso, no processo de revisão é possível verificar as partes em que a palavra da revisora é incorporada ao texto revisado. Examinar como ocorre essa prática é uma das nossas questões neste trabalho, bem como discutir como o processo de revisão revela características dessa atividade de trabalho.

\footnotetext{
8 Sobre as formas de transmissão do discurso alheio, na segunda parte de Marxismo e filosofia da linguagem, Volóchinov (2017) problematiza o "fenômeno da transmissão do discurso alheio em uma perspectiva sociológica" (p. 247) e aprofunda "a relação ativa de um enunciado com outro" e suas "formas construtivas estáveis da própria língua" (p. 251).
}

As ponderações, até aqui discutidas, sobre a perspectiva dialógica da linguagem, remetem à abordagem ergológica do trabalho, em especial ao enfoque relativo ao ser humano em situações reais e concretas. 0 tratamento da indissociável relação entre linguagem e trabalho, neste estudo, permite, por um lado, interrogar sobre a opacidade da linguagem e a invisibilidade do trabalho e, por outro, observar a importância dessa aproximação para a compreensão da atividade de revisão textual. Passemos, na próxima seção, à abordagem ergológica, que tem como objeto de estudo a atividade humana de trabalho.

\section{Abordagem ergológica do trabalho}

A ergologia é uma abordagem pluridisciplinar que, agregando filosofia, linguística, ergonomia da atividade, sociologia, dentre outras áreas, tem como objeto de reflexão a atividade humana de trabalho em sua complexidade. ${ }^{9}$ Tal abordagem pressupõe a aproximação a situações reais de trabalho, em que se consideram experiências e diálogos sobre as práticas dos contextos em que os mais variados trabalhos se desenvolvem e se (trans)formam. Segundo Schwartz, há uma espécie de alquimia indefinida, um espaço em que circulam diferentes histórias, valores e saberes: “[...] tudo tem de ser pensado, tem de ser visto, como consequência de certa abordagem da atividade humana" (2013, p. 329).

Ao focalizar a atividade humana de trabalho, a ergologia considera o trabalho como um fazer complexo e enigmático que ultrapassa os limites 9 A ergologia nasceu na França, na década de 1980, a partir da inquietação de um grupo de pesquisadores Provence Também contou com o apoio do ergonomista da atividade Jacques Duraffourg. As três Provence. Tamben contou com o apoio do ergonomista da atividade Jacques Duraffourg. As três principais influências na exgológica foram (i) a experiência de pesquisaem especial de Alain Wisner, e (iii) a filosofia de George Canguilhem (SCHWARTZ, 2006). 
daquilo que podemos perceber no desenvolvimento de dada tarefa. Desse modo, o trabalho estende-se ao que não é realizável, mas que também faz parte do universo de microescolhas feitas pelo ator da atividade, o trabalhador. Para a abordagem ergológica, toda a atividade de trabalho é perpassada por um debate contínuo entre as normas antecedentes (que preexistem a toda a atividade e englobam o conhecimento das práticas diárias e também teóricas) e as renormalizações (resultantes da capacidade humana de ressignificar a prática, a partir das circunstâncias concretas em que atua). Vivemos imersos nesse debate de normas, tendo em vista que "[...] temos de agir num mundo em que não criamos, saturado portanto por inúmeras normas antecedentes, de diversos níveis e graus de proximidade com as exigências do presente" (SCHWARTZ, 2014, p. 264).

Cabe ao ator da atividade administrar esse jogo de valores e normas na concretização do trabalho, considerando-se também que há níveis de invisibilidade - um "[...] nó de debates [muitos invisíveis] entre normas antecedentes e tentativas de renormalização na relação com o meio" -, em que emergem valores diversos, consensuais e contraditórios, em cenários específicos. Dada essa dinamicidade, própria da atividade humana, é impossível a submissão ao controle absoluto das normas antecedentes, já que o trabalhador sempre fará (re)ajustes conforme as necessidades de cada situação, ressingularizando as experiências a partir da sua individualidade e dos variados contextos nos quais está inserido. Por essa compreensão, entende-se que a atividade de trabalho "[...] é uma sequência de debates de normas, exigidos pela configuração das normas antecedentes, de um lado, e impossível e invivível do outro", que originam uma série de ressignificações, as renormalizações (SCHWARTZ, 2011, p. 34).

Para Schwartz (2014, p. 261), nesse cenário, as atividades humanas são "industriosas" e exigem "sempre escolhas de uso industrioso", o que obriga o trabalhador a enfrentar "uma dimensão em geral bem invisível do trabalho: toda sequência de atividades industriosas envolve arbitragens, debates, imersos num mundo social em que a comunidade de destino é sempre eminentemente problemática, em permanente reconstrução". Os resultados dessas arbitragens, as renormalizações, "mesmo num nível infinitamente pequeno", "recriam sem cessar uma história: 'ocorre continuamente algo novo' que, obrigando-nos a escolher, forçam-nos a nos escolher, na qualidade de seres às voltas com um mundo de valores". Em decorrência dessa postura, surge o "uso de si" como uma imposição contínua das escolhas permanentes, que possibilitam o entendimento da atividade de trabalho como "um encontro de dramáticas do uso de si, a de um agente no trabalho e a do usuário, do cliente, do paciente, do aluno etc.".

Entender o trabalho como uso de si é considerá-lo como "uso de um corposi". Há um "debate entre o uso de si por si e o uso de si por outros, a inevitável arbitragem, e, portanto, a presença de valores que possibilitam as escolhas, as resultantes das dramáticas em termos de recentramentos" (SCHWARTZ, 2014, p. 263). O corpo-si está ancorado em três dimensões indissociáveis: biológica (corpo com potencialidade e limites), histórica (debate de normas em um dado momento) e singular (experiência de vida de "um corpo desejante, em permanente tentativa de 'composição' e de apropriação [...] a fim de responder aos encontros e provas"). Trabalhar, nessa perspectiva, é "tentar estabelecer uma sinergia para essa tríplice ancoragem no tratamento dos debates de normas que se fazem incessantemente" (p. 264).

Esse debate de normas remete à relação entre trama e urdidura, desenvolvida por Daniellou e retomada por Duraffourg (2010) como um cruzamento constitutivo do trabalho. Enquanto a trama refere-se a um conjunto de procedimentos e meios, resultado de experiências capitalizadas em níveis econômicos, jurídicos, organizacionais etc., próprio das conjunturas de trabalho, a urdidura é o investimento de indivíduos singulares com histórias e experiências pessoais, "seus corpos e sua 
subjetividade, seus desejos e suas expectativas [...]". Essas reflexões põem em relevo a importância do reconhecimento do que Duraffourg chama de "dialética fundamental entre o singular e o geral", sob pena de se cair em uma das extremidades: focalização da forma abstrata dos fenômenos gerais, não considerando o concreto do trabalho, ou focalização estrita do singular, o concreto, sem relacioná-lo com o contexto maior (DURAFFOURG, 2010, p. 62; DI FANTI, 2014).

De acordo com a ergologia, há uma dupla antecipação da atividade que estabelece as práticas profissionais: os saberes instituídos (acadêmicos) e os saberes investidos (práticos). Nesse sentido, podemos dizer que atividade de trabalho é um espaço de encontro de saberes, mais especificamente, entre saberes acumulados nos instrumentos, nas técnicas, nos dispositivos coletivos, e saberes advindos da prática, da experiência cotidiana do fazer. Lidar com esses diferentes conhecimentos é articular, de um lado, “[...] saberes legitimamente descontextualizáveis [...] em relativa desaderência com, de outro lado, as 'surpresas', oriundas disso que há de inédito em toda experiência, inédito porque é aderente a uma situação histórica singular" (SCHWARTZ, 2013, p. 19). Os saberes em desaderência, que correspondem à primeira antecipação, são importantes na medida em que possibilitam considerar a relevância dos fatores históricos para o desenvolvimento das atividades, as "configurações estáveis de atividade, conhecíveis e analisáveis por recursos de diferentes saberes científicos, técnicos e sociais" e, também, as similaridades típicas de cada conjuntura profissional. Todavia, não se pode esquecer de que há uma dupla antecipação na atividade, e a primeira não pode, de maneira alguma, “[...] neutralizar as dimensões singulares que reproduzem e encontram, dia após dia, a prodigiosa fecundidade de todo agir humano" (SCHWARTZ, 2013, p. 21).

A partir desse ponto de vista, consideram-se as práticas linguageiras emergentes das situações de trabalho, desde as observadas in loco até aquelas decorrentes dos ambientes laborais, como um meio de acessar facetas da atividade e "[...] compreender como as atividades de trabalho transformam continuamente os espaços da vida, as maneiras de conceber a vida social" (SCHWARTZ, 2002, p. 113). Para tratar da relação entre linguagem e trabalho, Nouroudine (2002, p. 19) discorre sobre três dimensões interdependentes, em que a linguagem emerge como importante aliada nas investigações ao ser considerada como dispositivo revelador da complexidade do trabalho: ${ }^{10}$ a linguagem como trabalho, a linguagem no trabalho e a linguagem sobre o trabalho. A linguagem como trabalho é integrante do próprio fazer, por isso sua complexidade advém das várias dimensões intrínsecas envolvidas, desde as manifestações econômicas, sociais e políticas até os saberes e valores que se cruzam no trabalho. A linguagem no trabalho, por sua vez, é circundante e, nessa perspectiva, podem ser referidos os mais variados assuntos que não dizem respeito ao trabalho desenvolvido, mas que, tal como este, ocupam o espaço global de atuação dos trabalhadores e são tão importantes e significativos quanto a linguagem como trabalho, pois costumam funcionar como um mecanismo de manutenção da atividade. Já a linguagem sobre o trabalho contempla as trocas estabelecidas entre os atores do trabalho, tendo como objeto de reflexão a própria atividade, como comentário e explicação: "fala-se do trabalho para transmitir, avaliar, justificar, corrigir" (NOUROUDINE 2002, p. 26). ${ }^{11}$

Preocupar-se com variados usos da linguagem aproxima os pressupostos bakhtinianos dos ergológicos, pois ambas as perspectivas estão voltadas

${ }^{10}$ Nouroudine (2002), em A linguagem: dispositivo revelador da complexidade do trabalho, deixa claro que essa distinção não foi criada por ele, mas sim recuperada através de leitura de Lacoste (1995), a qual discorre sobre os estudos de Grant Johnson \& Caplan (1979) a esse respeito. ${ }_{11}$ Para Faïta (2002, p. 50), as três dimensões articuladas, embora possam parecer uma comodidade para
a análise, podem ser um auxílio metodológico importante ao analista do trabalho, considerando-se que a análise, podem ser um auxílio metodológico importante ao analista do trabalho, considerando-se que a atividade incorpora simultaneamente maneiras de dizer e "maneiras de agir orientadas a um objetivo
comum". 
para situações concretas da atividade humana, conduzidas por centros de valores interligados. Tratar da atividade, tendo em vista a inter-relação teórica proposta, é reconhecer que a linguagem e o trabalho se engendram em uma complexa rede, heterogênea e dialógica, protagonizada por sujeitos singulares. Considerando a atividade de trabalho como um fazer complexo e enigmático, passemos a problematizar o trabalho de revisão de tese de doutorado e observar pistas dessa atividade a partir de excertos de uma tese e respectivos comentários tanto da revisora, a profissional de revisão, quanto da doutoranda, a autora do trabalho.

\section{Movimentos de alteridade no processo de revisão: palavra própria e palavra do outro na teia dos sentidos}

O material de análise que compõe este artigo fez parte de uma pesquisa de doutorado defendida em 2017 no PPGL da PUCRS, a qual teve como objeto de investigação a atividade de trabalho do revisor de textos acadêmicos em teses (BARBOSA, 2017). O conjunto do material da pesquisa foi composto por correspondências eletrônicas trocadas entre duas revisoras e quatro autoras de teses revisadas; e trechos dos textos com os respectivos comentários inseridos via ferramenta de edição de textos no programa Microsoft Word durante o processo de revisão. ${ }^{12}$

Para esta reflexão, que propõe observar relações de alteridade a partir de interações entre uma revisora e uma doutoranda durante parte do processo de revisão textual, selecionamos um pequeno recorte de dois excertos da tese e os respectivos comentários inseridos nesses

${ }^{12} \mathrm{O}$ material utilizado na pesquisa foi aprovado pelo Comitê de Ética em Pesquisa da PUCRS, e os sujeitos participantes assinaram um Termo de Consentimento Livre e Esclarecido (TLCE), autorizando a utilização dos dados do trabalho na divulgação do conhecimento científico. A identificação dos sujeitos trechos pelas responsáveis por essa interação, ou seja, a revisora, que tem graduação e mestrado na área de letras, e a doutoranda que tem graduação em licenciatura em matemática, o mestrado em educação ambiental e o doutorado (em curso na época da revisão) na mesma área do mestrado. Nos trechos selecionados, podemos observar não só partes da escrita em debate, mas também os diálogos desenvolvidos entre a revisora e a doutoranda por meio dos comentários inseridos na escrita, o que permite vislumbrar aspectos do imbricamento entre a palavra da doutoranda e a da revisora na versão final da tese que passou pelo processo de revisão textual.

A fim de delimitar os lugares ocupados na análise em relação ao desenvolvimento da revisão, designamos de palavra própria os enunciados de responsabilidade da doutoranda, a autora da tese, e de palavra do outro os enunciados da revisora, já que se pretende ver, em última instância, como o outro, no caso a revisora, interfere no texto final da tese e como esse mecanismo revela características da atividade de revisão.

Sabemos, seguindo Bakhtin (2016a), que as noções de palavra própria e palavra do outro são dinâmicas e podem ser olhadas, alternativamente, em relação ao sujeito do discurso de referência. Ou seja, se o discurso de referência é o da revisora, podemos considerar como palavra própria o seu discurso em relação ao da doutoranda, que seria palavra do outro, e isso mudaria cada vez que alguém tomasse a palavra. Optamos, no entanto, por considerar como palavra própria o discurso da doutoranda, em função de ser ele o ponto de partida, isto é, o texto de referência da tese que será observado em relação à proposta de reescrita elaborada pela revisora e aos comentários da revisora, o outro nessa relação.

Passemos à análise, considerando os seguintes trechos no Recorte 1: trecho original enviado pela doutoranda, trecho reescrito com marcações da revisora, comentários da revisora, retorno da doutoranda e escrita da versão final. 
Recorte 1 - Interação entre a Revisora e a Doutoranda

\begin{tabular}{|c|c|c|}
\hline $\begin{array}{l}\text { Trecho com o texto original enviado } \\
\text { pela doutoranda }\end{array}$ & $\begin{array}{l}\text { Comentário da revisora no trecho } \\
\text { em questão }\end{array}$ & Retorno da doutoranda \\
\hline $\begin{array}{l}\text { "Percebemos que dizeres da educação estão } \\
\text { enraizados na educação da [Nome], por } \\
\text { causa de sua mãe que fez ela conceber a } \\
\text { educação como um espaço de experiência e } \\
\text { de oportunidade e transformação social, em } \\
\text { que o ouvir, diálogo e abertura se tornam } \\
\text { indissociáveis". }\end{array}$ & \multirow{3}{*}{$\begin{array}{l}\text { [Nome da Autora], fiz algumas modificações } \\
\text { em teu texto, conforme sublinhado. Peço } \\
\text { que revejas com calma para ver se mantive } \\
\text { os sentidos pretendidos por ti. Ok? } \\
\text { Outra coisa que queria te dizer é que, lendo } \\
\text { tuas análises e vendo o peso que dás à mãe } \\
\text { da [Nome], penso que, quando resumes a } \\
\text { história desse sujeito, lá na metodologia, } \\
\text { isto é, quando a [Nome] aparece pela } \\
\text { primeira vez, deverias deixar claro ao leitor } \\
\text { que há mais detalhes da trajetória dessa } \\
\text { protagonista que aparecerão no decorrer } \\
\text { do trabalho e serão fundamentais para a } \\
\text { compreensão dos objetivos da pesquisa. } \\
\text { Não? O que achas? } \\
\text { Lendo assim como está, confesso que } \\
\text { há uma surpresa ao leitor, quando } \\
\text { mencionas a mãe da [Nome] na história } \\
\text { dela, compreendes? Além disso, lá na } \\
\text { metodologia, sugiro também que deixes } \\
\text { claro de que modo conseguiste esses } \\
\text { dados sobre a vida dela, se foi através de } \\
\text { entrevista, de escrita de memorial, de } \\
\text { questionários etc. Não é bom que o teu } \\
\text { leitor seja surpreendido por novos dados } \\
\text { lá na análise do material. Por isso, sugiro } \\
\text { que retornes lá na metodologia e esclareças } \\
\text { esses pontos, certo? }\end{array}$} & $\begin{array}{l}\text { Revisora, ADOREIII a reescrita! Ficou ótima. } \\
\text { Obrigada! Sobre a metodologia, voltei nela } \\
\text { e fiz tudo o que você me falou. Depois vou } \\
\text { te mandar assim que minha orientadora } \\
\text { terminar a leitura, tah? Ela disse que gostou } \\
\text { do que você falou e que agora as coisas } \\
\text { estão fazendo mais sentido mesmo. Nossa, } \\
\text { MUITOOO OBRIGADA! }\end{array}$ \\
\hline $\begin{array}{l}\text { Trecho reescrito com marcações da } \\
\text { revisora (sublinhadas) }\end{array}$ & & Escrita da versão final \\
\hline $\begin{array}{l}\text { "Percebemos que as concepcões de ensino } \\
\text { reveladas pelos dizeres de [Nome] estão } \\
\text { enraizadąs na educação que recebeu de } \\
\text { sua mãe. Foi a sua progenitora que, a } \\
\text { partir das suas práticas de ensino, fez a } \\
\text { [Nome] conceber a educação como um } \\
\text { espaço de experiências e de oportunidade } \\
\text { de transformação social. Podemos dizer, } \\
\text { por isso, que ela cresceu em um contexto } \\
\text { no qual o ouvir, o diálogo e a abertura se } \\
\text { tornam indissociáveis". }\end{array}$ & & $\begin{array}{l}\text { "Percebemos que as concepções de ensino } \\
\text { reveladas pelos dizeres de [Nome] estão } \\
\text { enraizadas na educação que recebeu de } \\
\text { sua mãe. Foi a sua progenitora que, a } \\
\text { partir das suas práticas de ensino, fez a } \\
\text { [Nome] conceber a educação como um } \\
\text { espaço de experiência e de oportunidade } \\
\text { de transformação social. Podemos dizer, } \\
\text { por isso, que ela cresceu em um contexto } \\
\text { no qual o ouvir, o diálogo e a abertura se } \\
\text { tornam indissociáveis". }\end{array}$ \\
\hline
\end{tabular}

Fonte: (BARBOSA, 2017, p. 163).

Observando, conforme Bakhtin (2016a), a constituição dialógica dos enunciados, podemos dizer que tanto os enunciados da doutoranda como os da revisora instituem-se como elo na comunicação discursiva, já que vêm carregados de ecos e ressonâncias de enunciados já ditos ao mesmo tempo que antecipam possíveis respostas. Por um lado, o enunciado do trecho original da tese, ("Percebemos que dizeres da educação [...] em que o ouvir, diálogo e abertura se tornam indissociáveis [...]” (Doutoranda)), dialoga, por exemplo, tanto com o todo da pesquisa em desenvolvimento, a orientação recebida e as leituras efetuadas, quanto com possíveis concordâncias ou objeções do seu dizer, seja pela orientação e pela banca, seja por leitores da área. Ainda que não pareça estar no horizonte da doutoranda, nos enunciados da tese, a revisão efetuada por uma profissional da área de letras, é verdade que a produção do texto não deixa de considerar, em termos da perspectiva dialógica, a articulação entre as palavras da língua e as palavras próprias (em sua constituição heterogênea).

Por outro lado, o enunciado da revisora, referente ao trecho original da tese, além de dialogar com diferentes perspectivas de revisão textual e experiências na profissão, próprias das normas antecedentes, debruça-se sobre o enunciado da doutoranda para dar respostas pontuais a possíveis problemas encontrados ("fiz algumas modificações em teu texto [...] Peço que revejas com calma para ver se mantive os sentidos pretendidos por ti [...]" (Revisora)), direcionando seu dizer, de modo particular, à doutoranda e, de modo geral, à comunidade acadêmica.

Nessa alternância dos sujeitos do discurso, entendendo o texto como enunciado, representativo de um dado gênero (BAKHTIN, 2016a, 2016b), no caso de uma tese de doutorado, é possível perceber que as alterações, marcadas no trecho reescrito pela profissional de revisão, apontam adequações de diferentes ordens, como de composição, de estilo e de 
conteúdo temático. Comparando o texto original com o texto reescrito, percebe-se que houve um desenvolvimento substancial em relação ao desenvolvimento do enunciado: um período com 43 palavras passou a três períodos com 71 palavras. Na relação de alteridade empreendida entre a palavra da doutoranda (palavra própria) e a palavra da revisora (palavra do outro), observada no texto da tese, percebemos que a palavra do outro, no caso da revisora, insere-se no enunciado da doutoranda e dá novas tonalidades ao texto original. Podemos entender que o potencial criador da palavra do outro, da revisora, em relação ao texto da tese, revela o quanto a linguagem, no caso como trabalho, autoriza, seguindo Faïta (2010), a capitalização de experiências práticas, ou seja, revela saberes da revisora em sua prática profissional.

Ademais, o recorte em foco possibilita observar que a voz da revisora não se faz presente só nesse caso materialmente posto, mas também na reorganização de outras partes do texto, que já estavam dadas como concluídas pela autora da tese, como se observa a seguir:

Outra coisa que queria te dizer é que, lendo tuas análises e vendo o peso que dás à mãe da [Nome], penso que, quando resumes a história desse sujeito, lá na metodologia, isto é, quando a [Nome] aparece pela primeira vez, deverias deixar claro ao leitor que há mais detalhes da trajetória dessa protagonista que aparecerão no decorrer do trabalho e serão fundamentais para a compreensão dos objetivos da pesquisa. Não? 0 que achas? Lendo assim como está, confesso que há uma surpresa ao leitor, quando mencionas a mãe da [Nome] na história dela, compreendes? Além disso, lá na metodologia, sugiro também que deixes claro de que modo conseguiste esses dados sobre a vida dela, se foi através de entrevista, de escrita de memorial, de questionários etc. Não é bom que o teu leitor seja surpreendido por novos dados lá na análise do material. Por isso, sugiro que retornes lá na metodologia e esclareças esses pontos, certo? (Revisora). (grifos nosso)

Os acentos valorativos em evidência no enunciado-resposta da revisora orientam para uma visão do todo da tese, além da parte da análise revisada. Também apontam para uma compreensão responsiva, como entende Volóchinov (2017, p. 179), que "traduz o compreendido em um novo contexto, ou seja, em um contexto de uma possível resposta". Tal compreensão pode ser relacionada aos movimentos interdependentes de empatia e de exotopia, aproximação e distanciamento necessário para criação de conhecimento. Na medida em que a revisora faz uso da linguagem sobre o trabalho, tratando da metodologia e da importância de contextualizar a trajetória do sujeito de pesquisa da tese, revela o seu domínio do gênero focalizado e das relações exigidas com os destinatários desse gênero, que não podem ser surpreendidos com dados não apresentados anteriormente ("confesso que há uma surpresa ao leitor").

Essa percepção aponta para os saberes da profissional sobre o gênero tese, no que tange à constituição e o direcionamento do enunciado. Como afirma Bakhtin (2016a, p. 63), "as concepções do destinatário são determinadas pelo campo da atividade humana e da vida a que tal enunciado se refere". A reflexão da revisora mostra a influência que o destinatário da tese tem na construção do enunciado, do texto. Por isso, reage ao modo como a doutoranda percebe e representa seus destinatários: "Não é bom que o teu leitor seja surpreendido por novos dados lá na análise do material". No que tange à questão do destinatário, na relação de alteridade entre a revisora e a doutoranda, percebemos que, nas observações que formalizam os comentários sobre o texto analisado (linguagem sobre o trabalho), há escolhas cuidadosas dos elementos linguísticos de modo a se aproximar da doutoranda, como é o caso das escolhas verbais ("queria te dizer", "deverias deixar claro", "sugiro" etc.) e das perguntas retóricas ("não?”, “o que achas?”, “compreendes?", “certo?" etc.).

No trabalho da revisora, seguindo Trinquet (2010, p. 100), podemos perceber que os saberes investidos "servem de forças de convocação e 
reconvocação", o que faz emergir a sua experiência na microgestão da atividade, no retrabalho das normas antecedentes, pondo em relevo características da atividade concreta. Para chegar a esse tipo de intervenção e percepção da escrita, como destaca Oliveira (2007, p. 101), o revisor considera o texto em processo de revisão a partir dos dois polos que o constituem: o do enunciado e o da oração. Por esse procedimento "pode ajudar o autor a dar acabamento ao seu texto em uma perspectiva concretamente dialógica, levando em conta a maneira como o autor se posiciona diante do objeto/tema [...] e inter-relacionando às outras vozes no texto, além dos aspectos linguísticos e notacionais". Como explica Bakhtin (2016b), o texto pressupõe relações dialógicas com outros textos e no interior de um texto. No caso da revisão, podemos perceber o "encontro de dois textos do texto pronto e do texto a ser criado, que reage" (p. 76). Esse encontro remete ao "encontro de dramáticas do uso de si" (SCHWARTZ, 2014), que implica uma relação de alteridade entre a autora da tese e a revisora, que, no exercício profissional, é convocada a fazer escolhas, fazer uso de si, o que também ocorre com a doutoranda ao receber a revisão. Ela também terá de fazer escolhas: incorporar ou não ao seu texto as sugestões da revisora.

Nos enunciados correspondentes ao retorno da doutoranda sobre a revisão, percebemos reações ativas de acolhimento das sugestões, materializadas em acentos sociais de valor bastante positivos: "Revisora, ADOREIII a reescrita! Ficou ótima. Obrigada! Sobre a metodologia, voltei nela e fiz tudo o que você me falou. Depois vou te mandar assim que minha orientadora terminar a leitura, tah? Ela disse que gostou do que você falou e que agora as coisas estão fazendo mais sentido mesmo. Nossa, MUITOOO OBRIGADA!" (Doutoranda). Os signos ideológicos, "ADOREIII" (com letras garrafais e repetição do "i" no final), "ótima", "nossa" e "MUITOOO OBRIGADA!" (reiterando o agradecimento e marcando a última ocorrência com letras garrafais e repetição do "o" final da palavra "muito"), sinalizam a aproximação das interlocutoras. Ainda que a situação forme o enunciado, "obrigando-o a soar de um modo e não de outro", como entende Volóchinov (2017, p. 206), percebemos que a variação de tons nos enunciados revela a relação do locutor e o interlocutor na palavra.

Os enunciados da autora da tese apontam para o fato de a revisora desempenhar um papel ativo na (co)elaboração da escrita, uma vez que é responsável pelo surgimento de novas tessituras que compõem a produção final da tese. Como podemos perceber, há uma diversidade de aspectos invisíveis que subjazem à prática da atividade de um revisor de textos acadêmicos e que costumam passar despercebidos. Nessa atividade, como em todas as outras, há um debate entre o uso de si por si (as próprias escolhas) e o uso de si por outros (as normas antecedentes) que faz circular valores de diferentes ordens (SCHWARTZ, 2014). No caso em foco, podemos perceber um corpo-si engajado com as dimensões histórica, no que se refere à compreensão de tese de doutorado, por exemplo, e singular, como é o caso da concepção de revisão textual engendrada na atividade. Tanto uma dimensão como a outra fazem circular a tensa relação entre a trama (conhecimentos gerais) e a urdidura (investimento singular) (DURAFFOURG, 2010). Todo o investimento do trabalho da revisora é bastante marcado por grande parcela de invisibilidade, que, no debate de normas e valores, não tem o compartilhamento instituído com profissionais da área. ${ }^{13}$ Por ser um trabalho solitário, sem uma cultura de reconhecimento, possivelmente, ninguém mais, além da autora da tese e sua orientadora, tenha ciência, ainda que em parte, da dimensão da interferência da revisora na versão final da tese.

Na relação de alteridade entre as palavras da autora da tese e as palavras da revisora no texto da tese, podemos perceber, comparando a versão

${ }^{13}$ Schwartz (2011), em Conceituando o trabalho, o visível e o invisível, apresenta contribuições importantes sobre a invisibilidade do trabalho. 
original do texto, a versão reescrita pela revisora e a versão final da tese, que as sugestões de reescrita feitas pela profissional foram acatadas na íntegra pela doutoranda. As palavras da revisora (palavras do outro) foram totalmente integradas ao texto da doutoranda (palavras próprias), constituindo um entrelaçamento entre essas duas vozes, que, ao serem assimiladas pela autora da tese, vão parar no texto final como se pertencesse apenas a um sujeito.

É próprio do discurso ser constituído por outros discursos (aparentes ou não), como prevê o princípio dialógico. Isso não é diferente na elaboração de uma tese. No entanto, considerando o trabalho de revisão, o problema é de outra dimensão, uma vez que resulta de interações entre autora e revisora, que visam ao aprimoramento da versão final da tese. Nesse sentido, parece ser necessário trazer para discussão não os limites entre as palavras da doutoranda e da revisora na bivocalidade do texto final, já que as palavras do outro são inseridas no texto da tese pela revisora, que entende a revisão a partir da reformulação de enunciados. Interessa sim tratar do apagamento da voz da revisora que, ao não ser mencionada em nenhuma parte da escrita, não tem espaço para o reconhecimento da sua atividade, o que potencializa ainda mais a invisibilidade do trabalho.

Recorte 2 - Interação entre a Revisora e a Doutoranda

Trecho com o texto original enviado pela doutoranda

(As palavras em negrito correspondem à inserção de comentários pela revisora, os quais estão transcritos no quadro ao lado) "Durante sua adolescência, [Nome] se emocionava com histórias de degradação ${ }^{1}$ superaç̃o humana mas $^{2}$ envolvida por sua superção humana, maš paixão pelo mar $_{2}$ pela praia, pela sensaçăo de liberdade promovida pelo cheiro da maresia e pelo frescor do vento em um dia ensolarado ${ }^{3}$, ela conheceu e optou por cursar oceanografia. Quando ingressou na faculdade ${ }_{2}$ já nessa época, ${ }_{2}$ percebia, mesmo de forma tímida, que os movimentos ecológicos a encantavam, pois eram movimentos sociais em busca de mudanças para uma sociedade mais igualitária e não da ecologia em si".

\section{Trecho reescrito com marcações} da revisora (sublinhadas)

"4Durante a adolescência, [Nome] costumava se emocionar com histórias de vida das

pessoas principalmente se elas tratassem da capacidade humana de superac̃a o Contudo ainda que demonstrasse afinidade com

questões sociais, típicas de serem estudada questôs sociais, tipicas de serem estudadas muito elias Humanas, [Nome] era também pela praia, pela sensação de liberdade promovida pelo cheiro da maresia e pelo frescor do vento em dias ensolarados. Assim, movida por esse amor maior, foi que ela optou por cursar oceanografia. Para sua surpresa, no decorrer do curso, suas duas paixões puderam se unir. Isso aconteceu quando descobriu o conceito de movimentos ecológicos, o qual se referia a movimentos sociais em busca de mudanças para uma sociedade mais igualitária. Então, em vez de se dedicar a estudar definições exclusivas da ecologia em si, ela também pôde trabalhar em sua pesquisa com a área das Humanas".

Fonte: (BARBOSA, 2017, p. 166-167).
Comentário da revisora no trecho em questão

1) É isto mesmo: ela se emocionava também com histórias de degradação humana? Mas a degradação não é algo tão deprir triste? Não falas disso antes, só mencio coisas positivas na história de vida da [Nome] que vão influenciar na sua deci depois. Se for isso mesmo que queres dizer, como aproximar a degradação com humana?

Este trecho ficou confuso. Penso que deves Este trecho ficou confuso. Pe
suprimir o "degradação", ok?

2) Sugiro também que faças um elo entre essas duas colocações (a emoção com histórias de superação humana e a paixão histórias de superação humana e a paixar
pelo mar), para que possas manter a conjunção adversativa "mas". Caso contrário, não vejo uma relação entre ambas que sustente a oposição, compreendes? Em que medida se emocionar com histórias alheias tem de ser oposto a ter paixão pelo mar e seus componentes?

3) Qual a relevância da informação "em um dia ensolarado" para o que vais dizer no trecho? Proponho que faças a supressão dessa parte, já que não está acrescentando informação relevante ao texto. Concordas?

4) Não sei se compreendi o que queres dizer nesse parágrafo, mas, se for o que estou pensando, te sugiro a reescrita com minhas marcações sublinhadas. 
Passemos a observar uma segunda interação entre a revisora e a doutoranda (Recorte 2). No caso em questão, a doutoranda procura analisar, na tese em foco, o quanto a trajetória de vida do seu sujeito de pesquisa foi importante na escolha profissional, um sujeito dividido entre o amor pelos estudos das Ciências Humanas e a paixão pela área de Oceanografia. Como na análise precedente, são considerados: trecho original enviado pela doutoranda, trecho reescrito com marcações da revisora, comentários da revisora, retorno da doutoranda e escrita da versão final.

Ao analisar esse recorte da tese revisada, percebemos que a palavra do outro, no caso da profissional de revisão, tem significativo papel na reescrita do texto, já que a maioria das alterações sugeridas também vão ser incorporadas à versão final do trabalho. Se observarmos o trecho em sua versão original (84 palavras), quando chega para a revisora e, depois, a versão pós-revisão (143 palavras), passando de dois períodos para cinco, é possível perceber as intervenções da profissional, referentes à adequação ao gênero (composição, tema e estilo de linguagem), como os trechos sublinhados, que indicam substituições lexicais, inserção de nexos coesivos e maior desenvolvimento das ideias mencionadas pela autora do trabalho. Quase todas as sugestões de reescrita dadas pela revisora são aceitas pela doutoranda, o que mostra que é no imbricamento entre as palavras própria e do outro que vai se constituindo a tessitura do trabalho final e o consequente processo de instauração de sentidos no e do texto da tese.

Os comentários da revisora e as suas intervenções, articulando as dramáticas de uso de si, na tensão entre os saberes instituídos (acadêmicos) e os saberes investidos (práticos), conforme Schwartz (2013, 2014), mostram também que o trabalho realizado vai muito além das adequações do texto enviado à doutoranda. Para Salgado (2007, p. 146), a adequação gramatical é apenas uma parcela do fazer do revisor: "não se trata apenas de correção, mas de aperfeiçoamento e adequação de um texto escrito". Tal fazer exige do profissional conhecimento teórico suficiente para tratar das adequações estritamente linguísticas, mas também exige conhecimento amplo de mundo, vivências de leitura e experiências com esse fazer, a fim de saber como sugerir as modificações à autora. Dito de outro modo, é a união dessas diferentes habilidades técnicas e de trajetória profissional que dará os subsídios necessários para que o revisor possa encontrar um equilíbrio entre as sugestões de reescrita nos moldes do projeto enunciativo do locutor (no caso, a autora da tese) e as adequações de linguagem que se fizerem necessárias, o que permite dizer que, no trabalho de revisão, “[...] há regras de construção previstas e ditames a serem respeitados, mas também que esse 'respeito' será guiado por noções menos precisas, ainda que igualmente importantes e constitutivas das diretrizes de correção de um texto" (SALGADO, 2007, p. 146).

Passemos a observar os comentários da revisora sobre o seguinte trecho da tese em processo de revisão: "Durante sua adolescência, [Nome] se emocionava com histórias de degradação e superação humana, mas, envolvida por sua paixão pelo mar, pela praia, pela sensação de liberdade [...] ela conheceu e optou por cursar oceanografia". A profissional, valendose da linguagem sobre o trabalho, alerta a autora da pesquisa para um equívoco na utilização do signo ideológico "degradação" articulado por uma conjunção aditiva com o signo "superação humana". Em princípio, para um leitor que não conhece o contexto maior da escrita, isto é, o capítulo todo, torna-se possível pensar que não há problema em unir esses dois signos, já que ambos são passíveis de provocar emoções humanas. No entanto, para a profissional de revisão, que, via movimentos de empatia (aproximação) e exotopia (distanciamento), desenvolveu um excedente de visão (BAKHTIN, 2011), capaz de ver além do todo da tese, incluindo o projeto discursivo da autora da tese, a relação instaurada no segmento "degradação e superação 
humana" é impossível, já que não é coerente com as afirmações anteriores, tal como destaca a revisora:

É isto mesmo: ela se emocionava também com histórias de degradação humana? Mas a degradação não é algo tão deprimente e triste? Não falas disso antes, só mencionas coisas positivas na história de vida da [Nome] que vão influenciar na sua decisão depois. Se for isso mesmo que queres dizer, como aproximar a degradação com a emoção de histórias sobre superação humana? Este trecho ficou confuso. Penso que deves suprimir o "degradação", ok? (Revisora).

No enunciado-resposta da doutoranda, percebe-se a concordância com a observação: "[Revisora], eu tava viajando na parte da degradação, rsrsrsrs. Obrigada por perceber!”. Essas considerações, particularizadas por acentos valorativos singulares em signos como "eu tava viajando", "rsrsrsrs" e "obrigada por perceber", permitem compreender não só a aproximação discursiva da interlocutoras, mas também a importância do horizonte social compartilhado entre as participantes da interação, pois todo enunciado, como observa Volóchinov (2011, p. 166), “[...] reflete em si a interação social entre o falante, o ouvinte e o herói [de quem se fala], e vem a ser o produto e a fixação de sua interação viva no material da palavra".

Soma-se às questões desenvolvidas o fato de que a atividade de trabalho, tal como nos mostra a ergologia, é industriosa e exige escolhas do trabalhador, que o força a sempre renormalizar (SCHWARTZ, 2014). Então, por mais que a revisora "aprenda" em sua formação acadêmica que necessita sugerir reformulações em um texto, quando está desenvolvendo a revisão, por exemplo, tem de perceber que cada texto é único e demandará do revisor conhecimentos diversos para as diferentes possibilidades de reescrita que fará, assim como dependerá também da natureza das relações estabelecidas com o autor da escrita. A maneira como autora e revisora interagem é essencial para a concretização do trabalho, pois, seguindo
Schwartz (2011, p. 34), “[...] as renormalizações são as múltiplas gestões de variabilidades, de furo das normas, de tessitura de redes humanas, de canais de transmissão que toda situação de trabalho requer".

Nos enunciados sob responsabilidade da doutoranda, chamam atenção acentos valorativos inscritos na resposta à revisora da tese ("Adorei a tua reescrita, era isso mesmo que queria dizer. Vocês da Letras sabem fazer milagre com nossos textos, haha!"), que, além de darem um tom de reconhecimento ao trabalho de reescrita efetuado ("adorei", "milagre"), inter-relacionam-se com vozes sociais que associam o sucesso do trabalho de revisão com a formação na área de Letras. No entanto, ainda são poucas as pessoas que têm a dimensão da complexidade dos fatores envolvidos na realização da revisão de textos. Muitas delas acreditam que basta a formação em uma área X ou Y para que se consiga revisar qualquer escrita de maneira rápida e eficaz, pois o conhecimento técnico necessário, muitas vezes, na opinião dos leigos, preenche os requisitos para a concretização de uma boa revisão. Esses discursos de simplificação do trabalho filiam-se a vozes que acreditam que a graduação é a grande responsável pela maneira como a revisora atua, desconhecendo a complexidade do mundo do trabalho, o qual exige um ir além dos conhecimentos advindos dos bancos acadêmicos e dos saberes formais. É, nessa direção que a ergologia, seguindo Schwartz (2013, p. 21), entende a atividade a partir de duas antecipações: uma em desaderência e outra em aderência. Contesta-se a observação do trabalho apenas via saberes em desaderência, o que corresponderia, por exemplo, apenas aos recursos dos saberes científicos. É necessário, via saberes em aderência, fazer brotar as dimensões singulares, próprias do ser humano.

Observando as relações de alteridade entre a revisora e a doutoranda, percebemos no excerto em análise uma discordância entre as duas interlocutoras quanto à relevância de uma referência ao clima no texto da tese: "em um dia ensolarado, ela conheceu e optou por cursar oceanografia" 
(Doutoranda) e "Qual a relevância da informação 'em um dia ensolarado' para o que vais dizer no trecho? Proponho que faças a supressão dessa parte, já que não está acrescentando informação relevante ao texto. Concordas?" (Revisora). Embora se perceba a pergunta retórica no final do enunciado da revisora ("Concordas?"), amenizando o tom da observação, o embate é ratificado pela posição axiológica no enunciado-resposta da doutoranda: "Sobre o dia ensolarado, quero mantê-lo, porque, na minha área é fundamental considerar a importância do clima nas decisões, mostrar que o ambiente faz parte e influencia a nossa vida e tomadas de decisões, entende?". Esse embate permite perceber que são diferentes horizontes de valor sobre um mesmo objeto de dizer, o que vem ao encontro da observação de Bakhtin (2015b, p. 48) sobre o fato de se encontrar o objeto "sempre [...] contestado, avaliado" em um meio tenso e agitado de discursos, aproximando-se de uns, entrelaçando-se com outros e afastando-se ainda de outros. A revisora, mesmo tendo contestado o uso de "em um dia ensolarado", não o excluiu da reescrita proposta, integrou-o ao enunciado de forma mais geral ("pelo frescor do vento em dias ensolarados"), o que remete ao cuidado da profissional em respeitar a palavra da doutoranda no conjunto da tese.

$\mathrm{Na}$ sequência da interação entre a revisora e a doutoranda, ao observamos, via linguagem sobre o trabalho, o seguinte enunciado da revisora - "Não sei se compreendi o que queres dizer nesse parágrafo, mas, se for o que estou pensando, te sugiro a seguinte reescrita" -, compreendemos, pela valoração do discurso, o movimento de aproximação à doutoranda, ao mostrar as alterações realizadas, mesmo que modalizando seu dizer ao introduzir a reflexão: "não sei se compreendi o que queres dizer nesse parágrafo". 0 enunciado em foco, na cadeia dialógica dos discursos, em que se situam e emergem outros discursos, se relaciona ainda com vozes sociais que revelam uma perspectiva de atividade de revisão como um fazer co-construído na constante interação entre autor de texto e revisor, já que o profissional depende da palavra do autor para validar e poder dar prosseguimento a sua atividade.

\section{Considerações finais}

Este artigo, problematizando a atividade de trabalho do revisor de texto acadêmico, observou relações de alteridade entre uma revisora e uma doutoranda durante parte do processo de revisão da tese. Para tanto, foram analisados, via perspectivas dialógica e ergológica, dois excertos da referida tese e os comentários da revisora e da autora da tese. Por meio da linguagem como trabalho e sobre o trabalho, refletimos sobre a relação empreendida entre a palavra da revisora (considerada palavra do outro) e a palavra da doutoranda (considerada palavra própria), de modo a perceber como a palavra do outro insere-se nos enunciados da doutoranda e revela particularidades da atividade de revisão de texto acadêmico.

Percebemos que, nos movimentos interdependentes de empatia e exotopia com a palavra da doutoranda, a revisora assume uma posição responsável que, recorrendo a Bakhtin (2010, p. 66), podemos entender como aquela em que o contemplador compreende seu dever em relação ao objeto a ser compreendido, "a orientação que [precisa] assumir em relação a ele". Isso é perceptível não só nas interações entre revisora e doutoranda, em especial nos modos de tratamento e de explicação das escolhas feitas na revisão, mas também no modo de interferir no texto da tese, em que procura articular cada parte revisada com o todo do projeto enunciativo da pesquisa. Nessa mesma direção, percebemos como a revisora articula os saberes - instituídos e investidos - requisitados no desenvolvimento do trabalho, fazendo movimentar o debate de normas e as particularidades do seu fazer industrioso, como ensina Schwartz (2014). Ao demonstrar pleno 
domínio do gênero tese, por exemplo, observamos como os signos refletem, por um lado, conhecimento das normas antecedentes e refratam, por outro, particularização desse conhecimento ao considerar a constituição e o direcionamento na singularidade do enunciado, ou seja, a renormalização efetuada em situação concreta.

Esse debate de normas, observado na atividade de revisão, pode ser associado ao ato ético, responsável, discutido por Bakhtin (2010), como um evento, em que as dimensões gerais não se dissociam do acontecimento da vida. Essas características colocam o ser humano como centro de valor interligado a outros centros de valor. Nessa arquitetônica, emerge o trabalhador, constituído por um complexo corpo-si, que, na relação entre o uso de si pelo outro e uso de si por si, responsabiliza-se pelo ato, a atividade de revisão textual, de modo participativo, articulando a cultura e a vida nas relações dialógicas empreendidas com a doutoranda na atividade de revisão.

Na condução da reflexão, consideramos a revisora como o outro da relação de alteridade, partindo do princípio de que a tese é o objeto do discurso de responsabilidade da doutoranda e que é exposto para revisão. Melhor dizendo, a tese, constituída pelas palavras próprias da doutoranda, ainda que heterogêneas, foi exposta para a análise e interferência da profissional de revisão, que alterou trechos desse objeto do discurso com palavras outras não só como sugestões mas também como reformulações e propostas de novas tessituras, bastante trabalhadas, ao enunciado. 0 texto final foi se construindo por meio de constante debate entre a profissional de textos e a autora da tese a partir do imbricamento da palavra do outro (revisora) com a palavra própria (doutoranda), o que, além de qualificar a atividade em questão, mostrou que o trabalho se desenvolveu de forma bastante colaborativa.

Nessa articulação entre a palavra própria (da doutoranda) e a palavra do outro (da revisora), não se distingue, na versão final, quais são as palavras da doutoranda e quais são da revisora. Esse corpo-si complexo, esse outro, respondendo ativa e responsivamente aos enunciados da doutoranda e da comunidade acadêmica, analisa, questiona, sugere, retifica, estende, faz adequações, enfim, concede sua palavra. No debate de vozes e acentos emotivo-volitivos, o tom valorativo das palavras do outro é incorporado ao texto final, em consonância com o projeto enunciativo da tese, não deixando aparecer fronteiras entre os dizeres. A palavra do outro se torna palavra própria (da doutoranda) pela intervenção consentida desse outro.

Essa perspectiva de revisão de textos, ainda que tenha sido observada a partir de uma pequena amostra, não deixa de pôr em relevo o paradoxo entre a importante palavra do revisor e o apagamento de sua atividade. Na cultura acadêmica, ainda não há um espaço legitimado de reconhecimento do nome do profissional que atua na revisão de um dado trabalho, o que contribui para o silenciamento da revisão. Com esta reflexão, procuramos iluminar facetas dessa atividade dinâmica, complexa e necessária, que, mesmo se estabelecendo por grande grau de invisibilidade, instaura o revisor como um importante outro, constitutivo da teia dos sentidos construídos na versão final dos trabalhos revisados.

\section{Referências}

BAKHTIN, Mikhail. Os gêneros do discurso (1952-1953). Trad. Paulo Bezerra. Rio de Janeiro: Editora 34, 2016a.

BAKHTIN, Mikhail. O texto na linguística, na filologia e em outras ciências humanas: um experimento de análise filosófica (1959-1961). Trad. Paulo Bezerra. Rio de Janeiro: Editora 34, 2016b.

BAKHTIN, Mikhail. Problemas da poética de Dostoiévski (1963). Trad. Paulo Bezerra. 5. ed. Rio de Janeiro: Forense, 2015a.

BAKHTIN, Mikhail. Teoria do romance I: A estilística (1930-1936). Org. da edição russa de Serguei Botcharov e Vadim Kójinov. Tradução, prefácio, notas e glossário de Paulo Bezerra. São Paulo: Editora 34, 2015b. 
BAKHTIN, Mikhail. O autor e a personagem na atividade estética. In: Estética da criação verbal [1979]. Trad. Paulo Bezerra. 6. ed. São Paulo: Martins Fontes, 2011. p. 21-90.

BAKHTIN, Mikhail. Para uma filosofia do ato responsável (1920-1924/1986). Trad. Valdemir Miotello e Carlos A. Faraco. São Carlos: Pedro \& João Editores, 2010.

BARBOSA, Vanessa Fonseca. Uma voz apagada? Análise da atividade de revisão de textos acadêmicos sob as perspectivas bakhtiniana e ergológica. Tese (Doutorado em Linguística) - Escola de Humanidades, Pontifícia Universidade Católica do Rio Grande do Sul, Porto Alegre, 2017.

BARBOSA, Vanessa Fonseca. Uma análise dialógica da atividade de revisão linguística em EaD. Dissertação (Mestrado em Linguística Aplicada) - Universidade Católica de Pelotas, Pelotas, 2012.

BARBOSA, Vanessa Fonseca; DI FANTI, Maria da Glória Corrêa. Entre aproximações e distanciamentos: movimentos dialógicos da atividade de trabalho do revisor de textos acadêmicos In: JÚNIOR, A. F.; STAFUZZA, G. B. (Org.). Discursividades contemporâneas: política, corpo, diálogo. Campinas (SP): Mercado de Letras, 2017. p. 255-286.

DI FANTI, Maria da Glória Corrêa. Discurso, dialogismo e atividade de trabalho: a constitutiva e tensa relação com o outro. In: DI FANTI, M. G. C.; BRANDÃO, H. N. (Org.). Discurso: tessituras de linguagem e trabalho. São Paulo: Cortez, 2017. p. 89-126.

DI FANTI, Maria da Glória Corrêa. Linguagem e trabalho: diálogos entre estudos discursivos e ergológicos. Letras de Hoje, v. 49, p. 253-258, 2014. https://doi.org/ 10.15448/1984-7726.2014.3.19111

DI FANTI, Maria da Glória Corrêa. Perspective dialogique et approche ergologique: (inter)faces de la relation Langage-Travail. Revue Ergologia. v. 9, p. 29-44, 2013.

DI FANTI, Maria da Glória Corrêa. Linguagem e trabalho: diálogo entre a translinguística e a ergologia. Desenredo, Revista do Programa de Pós-Graduação da Universidade de Passo Fundo, n. 1, v.8, 2012, p. 309-329.

DI FANTI, Maria da Glória Corrêa. A tessitura plurivocal do trabalho: efeitos monológicos e dialógicos em tensão. Alfa: Revista de Linguística (UNESP), v. 49, p. 19-40, 2005.

DURAFFOURG, Jacques. O trabalho e o ponto de vista da atividade. (Uma conversa entre Jacques Duraffourg, Marcelle Duc e Louis Durrive). Trad. Ana Luiza Telles e Eliza Echternacht. In: SCHWARTZ, Y.; DURRIVE, L. (Org.). Trabalho \& ergologia: conversas sobre a atividade humana. Niterói: EdUFF, 2010.
FARACO, Carlos Alberto. Linguagem \& diálogo: as ideias linguísticas do círculo de Bakhtin. São Paulo: Parábola, 2009.

FAÏTA, Daniel. A linguagem como atividade. (Uma conversa entre Daniel Faïta, Christine Noël e Louis Durrive). Trad. Maria da Glória Di Fanti e Maristela França. In: SCHWARTZ, Y.; DURRIVE, L. (Org.), Trabalho \& ergologia: conversas sobre a atividade humana. 2. ed. Coord. da tradução e revisão técnica de Jussara Brito e Milton Athayde. Niterói: EdUFF, 2010.

FAÏTA, Daniel. Análise das práticas linguageiras e situações de trabalho: uma renovação metodológica imposta pelo objeto. In: SILVA, M.C.S.; FAÏTA, D. (Org.). Linguagem e Trabalho: construção de objetos de análise no Brasil e na França. São Paulo: Cortez, 2002, p. 45-60.

NOUROUDINE, Abdallah. A linguagem: dispositivo revelador da complexidade do trabalho. In: SOUZA-E-SILVA, M. C.; FAÏTA, D. (Org.). Linguagem e Trabalho: construção de objetos de análise no Brasil e na França. São Paulo: Cortez, 2002. p. 17-30.

OLIVEIRA, Risoleide Rosa Freire de. Um olhar dialógico sobre a atividade de revisão de textos escritos: entrelaçando dizeres e fazeres. Tese (Doutorado em Linguística Aplicada) - Universidade Federal do Rio Grande do Norte. Natal, 2007.

SALGADO, L. S. Ritos genéticos no mercado editorial: autoria e práticas de textualização. Tese (Doutorado em Linguística) - Instituto de Estudos da Linguagem, Universidade Estadual de Campinas, Campinas, 2007.

SCHWARTZ, Yves. Motivações do conceito de corpo-si: corpo-si, atividade, experiência. In: DI FANTI, Maria da Glória Corrêa; SOUZA-E-SILVA, Maria Cecília de; SCHWARTZ, Yves. Letras de Hoje, Porto Alegre: EDIPUCRS, volume 49, número 3. 2014, p. 259-274.

SCHWARTZ, Yves. Entrevista. Revista Reflexão \& Ação, Santa Cruz do Sul, v. 21, n. 1, 2013, p. 329-339.

SCHWARTZ, Yves. Conceituando o trabalho, o visível e o invisível. Trabalho, Educação e Saúde, Rio de Janeiro, v. 9, supl. 1, 2011, p. 19-45.

SCHWARTZ, Yves. Entrevista. Revista trabalho, educação e saúde, Rio de Janeiro, Fundação Oswaldo Cruz, v. 4, n. 2, p. 457-466, 2006.

SCHWARTZ, Yves. A abordagem do trabalho reconfigura nossa relação com os saberes acadêmicos: as antecipações do trabalho. In: SOUZA-E-SILVA, M. C.; FAÏTA, D. (Org.) Linguagem e trabalho: construção de objetos de análise no Brasil e na França. São Paulo: Cortez, 2002. p. 109-126. 
SCHWARTZ, Yves; DI FANTI, Maria da Glória Corrêa; BARBOSA, Vanessa Fonseca. Uma entrevista com Yves Schwartz. Letrônica, Porto Alegre: EDIPUCRS, v. 9, n. especial, p. 222-233, 2016.

TRINQUET, Pierre. Trabalho e educação: o método ergológico. Revista Histedbr, número especial, p. 93-113, 2010.

VOLÓCHINOV, Valentin. Marxismo e filosofia da linguagem: problemas fundamentais do método sociológico na ciência da linguagem (1929). Trad., notas e glossário de Sheila Grillo e Ekaterina Vólkova Aérico. São Paulo: Editora 34, 2017.

VOLOCHINOV, Valentin. A palavra na vida e na poesia: introdução ao problema da poética sociológica (1926). In: Palavra própria e palavra outra na sintaxe da enunciação. Trad. Allan Pugliese, Camila Scherma, Carlos Turati, Fabrício Oliveira, Marina Figueiredo, Regina Silva e Valdemir Miotello. São Carlos: Pedro \& João editores, 2011.

Recebido em 16/02/2018.

Aceito em 10/05/2018. 